\title{
The Gender Gap in STEM Fields: Theories, Movements, and Ideas to Engage Girls in STEM
}

\author{
Anni Reinking ${ }^{1 *}$, Barbara Martin² \\ 1Department of Teaching and Learning, Southern Illinois University Edwardsville, USA \{anreink@siue.edu\} \\ Elementary Education Department, Southern Illinois University Edwardsville, USA \{barmart@siue.edu\} \\ Received on 19 December 2017; revised on 02 March 2018; accepted on 03 April 2018; published on 15 July 2018
}

DOI: 10.7821/naer.2018.7.271

(c))BY-NC-ND

\begin{abstract}
The 2010 President's Council of Advisors on Science and Technology indicated that there was a need to provide individuals with strong STEM (Science, Technology, Engineering, and Mathematics) backgrounds in order to be a competitive country internationally. Additionally, it has been found that there is a gender gap in STEM related fields. Therefore, this article describes theories related to the gender gap in the STEM field and ways to engage girls in STEM related fields in order to close the gender gap. The researchers of this study did extensive research to review the current literature, condense and summarize the findings from various studies, and provide steps for educators to engage in that will create an early atmosphere of positive learning environments for girls to be curious about STEM concepts.
\end{abstract}

KEYWORDS: STEM, GENDER GAP, SOCIALIZATION, TEACHERS

\section{INTRODUCTION}

Science, technology, engineering, and math (STEM) concepts have been shown to support the development of a generation of thinkers, collaborators, and problem solvers. However, research has shown that while STEM is an important aspect in academic and social capital, gender discrepancies have been found. While current research displays a gender gap focused within the concepts of STEM, the overall gender gap has decreased over generations. Specifically, since the early 1990's, the number of women who have earned their bachelor's, master's or doctoral degrees in STEM fields in the United States has increased (Hill, Corbett, \& St. Rose, 2010). However, even when females perform as well or better than their male peers on STEM related tests or projects, females lose interest at a higher rate and do not pursue advance courses, majors, and careers in STEM. Furthermore, in 2008, 41 percent of college freshman men planned to major in science and engineering, compared to 30 percent of women (National Science Foundation's Women, Minorities, and Persons with Disabilities in Science and Enginee- ring report). The question many researchers and professionals in the STEM field ask is, "Why is there a gender gap?"

Investigating the research even further displays not only a gender gap in students' choice of majors in higher education, but it also transfers to the work place. Research shows that female faculty members in higher education "still represent approximately one in five faculty members employed in computer science, mathematics, engineering, and the physical sciences collectively" (Girls, Inc., 2016, para 2). In STEM specific workplaces, such as the engineering field, the science field, the math field, and the technology field, men still hold more jobs than women. For example, the Society of Women Engineers states that in 2003 approximately $20 \%(\sim 12,000)$ of new engineers were women, compared with about $80 \%$ of men $(\sim 49,000)$, however this is an increase from generations past (Crawford, 2012).

Therefore, there is a recognized phenomenon in society that advances men in fields related to STEM while discouraging or leaving women behind. While this phenomenon has been studied for generations, there is still a wide range of theories to understand the gender gap in STEM fields. So, researchers and STEM professionals again ask the question, "Why is there a gender gap in STEM fields?" While this question is not answered in this specific article, ideas, research, and mindsets regarding this phenomenon are investigated and explained. As is evident in this article, there is still a wide range of explanations.

Researchers, scientists, and other professionals who have questioned this phenomenon have found that historically males have been incentivized to perform well in STEM related subjects while women have been incentivized to perform well in other subjects areas (Burton, 1986). Supporting this research is the fact that outside factors, such as parents, courses, teachers, and society, influence likes and dislikes for gender, which is known as gendered socialization (Leaper, 2014; Partridge, Brustard, \& Stellino, 2008). One of the socialization aspects for generations is the fact that women have not been encouraged to pursue STEM interests. Therefore, after recognizing the known phenomenon of fewer women than men in STEM professions, this review will discuss

\footnotetext{
*To whom correspondence should be addressed:

Southern Illinois University Edwardsville

Campus Box 1122

Edwardsville, IL 62026
} 
and examine why and how. Why is there a lower female representation in the fields related to STEM topics? How can educators increase girls' curiosity in STEM content? Additionally, current movements will be described as avenues to close the gender gap in STEM fields.

\section{METHODOLOGY}

The qualitative methodology used in this research study was summative content analysis of previous research studies (Hsieh \& Shannon, 2005). "A summative content analysis involves counting and comparisons, usually of keywords or content, followed by the interpretation of the underlying context" (Hsieh \& Shannon, 2005, p. 1277). During and after the content analysis process, the researchers were able to find common themes through the process of coding, specifically focused on theories related to the gender gap and strategies to engage girls in the STEM field at an early age.

The purpose of this study was to investigate and summarize current scholarship focused on girls and STEM. The research questions for this study include:

(1) What theories describe and explain the phenomenon of the gender gap in the STEM field?

(2) What strategies or ideas are available for girls to engage in STEM concepts?

(3) How can educators assist in closing the gender gap in the STEM field?

The three guiding research questions served as a guide during the data analysis and coding process.

After solidifying the three guiding research questions, the researchers began the research process. Initially, the researchers gathered articles and applicable information through data search sites. The terms used to search included, but were not limited to, "STEM", "Gender Gap", "Girls", "Education" and "Teaching". The researchers then began reading, summarizing, and coding the available scholarship available from 2005 to 2017.

The themes that were found, during and after the coding process, focused on the purpose of this study: to understand, investigate, and provide guidance on closing the gender gap in the field of STEM. The founding themes were also aimed at answering the three guiding research questions. The three founding themes included the theories describing why there is a gender gap in STEM, movements and strategies to engage girls in STEM, and how educators can engage students as a way to close the gender gap in STEM.

\section{FINDINGS}

Our findings will be described in this section, which were obtained after analyzing the available literature focused on girls and STEM. The guiding research questions and purpose of the study were used as guiding points throughout the research.

\subsection{STEM Gender Gap Theories}

The lack of female representation in STEM fields has been shown to have many possible starting points. Each one will be summarized, as well as explained in a deeper format. Some believe the gender gap is a direct response to stereotypes and socialization practices in the United States and other countries focused on male dominance and female submissiveness. Supporting the idea of socialization and societally engrained stereotypes also focuses on the gender socialization practices that occur in childhood such as boys are smart in math and girls are good in the kitchen (Gunderson et al., 2011; Regner, Steele, Ambady, Thinus-Blanc, \& Huguet, 2014). These socialization practices feed into the concept of stereotype threat, which can undermine girls' performance in STEM fields (Shapiro \& Williams, 2012).

Other researchers believe that the gender gap is not necessarily due to socialization and stereotype threat practices. Some believe the gender gap in STEM is directly linked to the role peer groups play in the academic experiences of students (Crosnoe, Riegle-Crumb, Field, Frank, \& Muller, 2008). Essentially this idea states that students enjoy being part of a peer group and would rather engage in similar activities as their peer groups than engage in activities that may not coincide with the "in group" perception from their peers' point of view.

The final theory related to the gender gap in STEM fields focuses stereotypes again, but more on the stereotypes of the professionals who work in the STEM fields (Cheryan, Master, \& Melzoff, 2015). This last theory focuses on the personality traits and characteristics that are stereotypical of technology professionals or engineers, which include social awkwardness or an introverted character (Cheryan, Master, \& Melzoff, 2015). These professional stereotypes infiltrate society's views of STEM related professionals, which may directly oppose the desired personality traits for women who are more social and outgoing.

\subsubsection{Theory 1: Gendered Socialization}

Overwhelmingly, girls and boys are socialized differently in the United States. This is generally based on preconceived ideas of gender roles. Gender roles are sets of "behaviors, attitudes, and personality characteristics expected and encouraged of a person based on his or her sex." What has been found is that, "boys are raised to conform to the male gender role, and girls are raised to conform to the female gender role" (SparkNotes, 2006, para 1). While experts still do not agree if the socialization and stereotypes of gender is based in genetic differences, the socialization practices are apparent from an early age.

The ideas of gender roles and socialization relate directly to the concept of the STEM field gender gap because researchers have continually found evidence of gender stereotypes related to STEM professions. Two researchers, Dasgupta and Stout (2014), found that women are leaving the STEM pipeline before entering the official STEM profession. This STEM pipeline phenomenon loses women who could become the next generation of scientists, engineers, and creators of technology. Researchers have found that one of the reasons women are leaving the STEM pipeline and professional field is because women are bombarded with socialized ideas and negative stereotypes, specifically about women's subpar math abilities (Gunderson et al., 2011). It has been found that these mentalities and stereotypes are communicated to girls at a young age through their parents and teachers, sometimes unconsciously. Regardless of the conscious or unconscious nature of the mentalities, these gendered stereotypes shape girls' math attitudes and ultimately diminish their interest in STEM fields. It can be argued that stereotypes and stereotype threats are two reasons why women are underrepresented in STEM fields.

Socialization also occurs in family contexts. Parents and/or guardians who raise children have an influence on their motivation when it comes to achievement in settings such as those structured around STEM related topics (Partridge, Brustard, \& Stellino, 2008). Specifically, Eccles (2014) describes and analyses "families' influences on gender differences in STEM disciplines" (p. 116). In her research she describes how parents' beliefs and 
perceptions influence children's outcomes and activity choices. Parents influence children through their advice, the materials (i.e. toys) available, and exposure to a variety of experiences. In her research she found that "parents do make gender-stereotypic causal attributions and these differences help to explain... children's abilities and interests" (p. 126). Overall, Eccles's research (2014), along with other research, displays the theory of gender socialization which marginalizes women in STEM fields. The marginalization diminishes women's voice and legitimacy in the workforce and classroom (Regner, Steele, Ambady, ThinusBlanc, \& Huguet, 2014).

\subsubsection{Theory 2: Peer Groups}

While socialization may play a role in the leaky pipeline for girls in STEM fields, other researchers focus on the peer relationships and pressure felt in the adolescent years. It was found that,

For all adolescents, math course taking was associated with the achievement of their close friends and, to a lesser extent, their course mates. These associations tended to be stronger toward the end of high school and weaker among adolescents with a prior record of failure in school. Each of these patterns was somewhat more consistent among girls (Crosnoe, Riegle-Crumb, Field, Frank, \& Muller, 2008, p. 139).

Essentially, this research states that during the difficult years of adolescence, (middle school) students want to perform as well as their peers, which could be associated with the "in group" acceptance that is critically important during the adolescent years. This research is also supported by other scholars. Specifically, You (2011) found "that peers have an important influence on the behavior and development of adolescents" (p. 829). Essentially, "the child's acceptance within the peer group is one of the key measures of positive/negative school experiences. Perceived support from peers can give students a sense of motivation and help students see the importance of pursuing academic success" (You, 2011, p. 829), such as STEM related courses.

Additionally, researchers van Hoorn, van Dijk, Meuwese, Rieffe, and Crone (2014) studied the influence of peers on adolescent behavior. While their study focused specifically on prosocial and antisocial behavior, the results support the idea that adolescents are influenced by peers and are vulnerable to peer feedback. When peers provide positive feedback, the behavior of peers increased to more prosocial behaviors. However, when peers give no feedback or antisocial feedback, positive behaviors decrease. Adolescents rely on peers and their judgments to know what to do, how to engage in their school/community, and to know what will be deemed "cool" or "uncool." Therefore, when very few gir1s enter STEM content courses, the peer feedback, through words or inaction, can be perceived as negative. Supporting this idea, researchers Leaper, Farkas and Bloom (2011), found that girls' motivation in math and science courses during the adolescent years is positively associated to peer support. Overall, peer groups have been found to influence the academic success of individuals. However, the peer group influence can also turn girls away from STEM courses if their "in group" does not academically succeed in the STEM related courses. Overall, peers play an important role in the engagement or disengagement in STEM related courses.

\subsubsection{Theory 3: Stereotypes of STEM Professionals}

While socialization and stereotypes at a young age could influence the eventual career path of a student, a group of researchers decided to view the lack of women in the field of STEM from another perspective. Specifically, a group of researchers focused on the representation or view of the culture surrounding STEM careers. In one study, three researchers proposed 'that students' stereotypes about the culture of these fields - including the kind of people, the work involved, and the values of the field-steer girls away from choosing to enter them" (Cheryan, Master, \& Melzoff, 2015, p. 49). Specifically, these researchers studied the stereotypes associated with computer science professionals, information technology professionals, and other STEM professionals. What they found was that while professions under the STEM umbrella seem more male-oriented, they also seem to involve the characteristic of social isolation.

The idea of social isolation as a career characteristic is directly associated to the first theory of gender socialization. Specifically, the learned behavior of women is that social isolation is not a valued quality within the female gender. Girls are socialized to be social beings, pleasers, and interactors. Furthermore, it was found that women are not historically socialized or taught that they are born with brilliance, while males in American society are socialized with the understanding that they are born with brilliance (Cheryan, Master, \& Melzoff, 2015). Therefore, if stereotypes associated to the work culture for STEM professionals changed or broadened, girls may be more interested in the career paths related to STEM.

Furthermore, Steinke (2017) researched how adolescent girls can develop identities, positive or negative, focused on STEM that can influence their professional choices later in life. One of the ways the researcher suggested as a way to increase girls' perception of STEM professions was through the incorporation of images and portrayals of women in STEM fields throughout media. Steinke began her research with this statement: "Popular media have played a crucial role in the construction, representation, reproduction, and transmission of stereotypes of STEM professionals" (p. 716). In her research she described what gender-stereotypes images are being portrayed to children, specifically girls, through media.

Additionally, more resent research has found that if women combat the stereotypes associated with their gender and develop a mindset of confidence, the gender gap may close at a quicker pace. Dr. Anna Powers, a leader in the world of STEM, provides women access to fields that drive innovation, studies, lectures, and empowers women and girls to focus on STEM topics. She advocates for girls to embrace STEM concepts by encouraging goal setting, confidence, and combatting assumed and historically rooted stereotypes (Kerpen, 2017).

\subsection{Engaging Girls in STEM Fields}

Overall, the three outlined theories focus on socialization, stereotypes, and the influence of peers. If stereotypes and mindsets are changed, there could be a significant increase in girls' sense of belonging in STEM professions. However, changing mindsets is not an easy task. There are many organizations and educational professionals striving to change mindsets as a way to engage and increase girls' interest in STEM fields. Specifically, there are movements and educational practices currently happening. Additionally, businesses, organizations, and schools are working to widen the view of what an engineer and/or scientist looks like and sounds like.

\subsubsection{STEM Movements}

Women who work in fields that incorporate STEM, along with other business leaders, have begun a movement to engage girls in science, technology, engineering, and mathematics. One orga- 
nization, Girls, Inc. (2016), “develops girls’ enthusiasm for skills in science, technology, engineering, and mathematics (STEM). Through hands-on activities, girls explore, ask questions, persist, and solve problems. By interacting with women and men pursuing STEM careers, girls come to view these careers as exciting and realistic options for themselves" (para 3). Furthermore, Girls, Inc. (2016) attributes their success to a mindset, specifically that all girls are interested in STEM. This mindset combats the current social message girls hear and see on a daily basis: science and math are not for girls.

Another resource is a website titled Engineer Girl. The entire website is focused on women engineers in history, what engineers can do, the steps to take to become an engineer, what an engineer is, and has an open forum to ask an engineer a question. On their website they answer the question, Why focus on girls? Their answer is,

Because despite an increase in female participation in many traditionally male-dominated professions such as medicine and law, women remain grossly underrepresented in engineering. Engineering and engineers are central to the process of innovation, and innovation drives economic growth. Diversity of thought is crucial to creativity, and by leaving women out of the process of innovation we lose a key component of diversity and stifle innovation (National Academy of Engineering, 2017, n,p.).

Furthermore, Lego, a brand toy arguably aimed at boys for many years, has begun their own movement to encourage girls to build and design. In 2011, 90\% of Lego's consumers were boys. When Lego discovered this statistics, they began to research and design Legos for girls. Through their research, Lego designers discovered that girls enjoy small details. After four years of research and design, this company released their Lego sets aimed to engage girls in engineering feats (Ulaby, 2013).

Another company called the GoldieBlox Company (2017) has taken the Lego idea one step further by designing and advertising to girls. On their "About Us" page they begin by stating, through a graphic, that only $14 \%$ of the engineers worldwide are female. This is something GoldieBlox is out to change. Through the GoldieBlox box sets girls are encouraged to build a functioning machine. The boxes range from preschool all the way up to teens and adults. It is a way for girls to become engaged through the character, GoldieBlox, and to build and make a functioning machine.

\subsubsection{Educational Strategies}

While national and international movements are one way to effect change, educators can also make an impact through teaching strategies and curriculum. Specifically, when educators use the aforementioned movements as a way to educate themselves and engage students, girls are hearing and seeing the world from many perspectives, and hopefully changing stereotypes. Therefore, through these movements, projects, and websites, educators, scientists, professionals, and others in the field of STEM are reaching out to girls. These projects are encouraging girls to be interested in STEM related projects and they are helping girls envision themselves as women in the field of science, mathematics, technology, and/or engineering. While organizations, companies, and websites have increased their mission to engage girls in STEM related subject areas, teachers can also influence girls entering the STEM field. Debbie Sterling, the founder of GoldieBlox (2017), stated on her website that,
She never knew what engineering was until her high school math teacher suggested she pursue it as a college major. Debbie couldn't figure out why her math teacher thought she should be a train conductor! Nevertheless, she gave engineering a try during her freshman year at Stanford. Four years later, she graduated with a degree in Mechanical Engineering / Product Design (n.p).

Teachers can encourage, teachers can engage, and teachers can ensure that girls are pursuing STEM related careers.

\subsection{Teachers' Next Steps}

While Debbie's anecdote about her teacher encouraging her to go into engineering as she was leaving high school may represent some teachers and parents around the country, it is also important to recognize that teachers of young students can also encourage, incorporate, and expose girls to STEM topics. Teachers can provide experiences, expose children to female STEM role models, create hands-on, safe environments for exploration, and combat societal gendered stereotypes. Understanding the importance teachers can play in the lives of children, below is a list of suggestions teachers can incorporate from early childhood through high school to encourage girls to enter and engage in STEM related fields.

\subsubsection{Provide Experiences}

One way educators can engage in changing gender stereotypes is through providing experiences. It is important that girls have experiences that involve building, trial and error, figuring out problems that relate to the real world, and working together. Andrea Guendelman, the co-founder of Developher, stated in an article published by CNN (Parke, 2014) that "A huge part of the reason women are not entering these fields and huge part of the solution starts at the very beginning" (para 5). The very beginning is how girls are introduced to STEM subjects. Introductions and handson experiences must be engaging for them or it is just viewed as another mundane, read from the book experience.

According to Dasgupta and Stout (2014), girls are more interested in math instruction taught from an applied, hands-on perspective than boys. Therefore, providing these experiences is critical to keeping girls interested in the STEM field. In fact, getting out of the textbook and into the messiness, sometimes controlled chaos, and problem solving of STEM has shown to engage girls at a higher level. Supporting this notion, Hayden, Ouyang, Scinski, Olszewski, \& Bielefeldt (2011), found that at the end of their hands-on STEM camp, most girls expressed having a higher confidence and more positive understanding of STEM topics such as engineering. The girls were able to experience, see, feel, fail, solve, and apply their knowledge to applicable hands-on encounters.

\subsubsection{Role Models}

Additionally, while providing experiences, educators can display and offer information about female role models in STEM related fields. Recent research by Hughes, Nzekwe and Molyneaux (2013), found that the girls' interest increased, along with an improved self-concept related to STEM fields when they were exposed to positive STEM role models that looked like them. In other words, girls were able to see females working as scientists, engineers, astrophysicists, computer programmers, and so forth. This research illustrates the importance of exposure to wo- 
men role models in the development of interest and the ability to self-actualize a girl's potential future in STEM fields.

There are a wide variety of resources such as research, articles and websites, as well as local professionals who are women in the fields of STEM. Find an engineer, or talk about famous female scientists, or even find books that depict real-life female scientists and their journey. Show girls that women can do it, be it, and succeed. Once girls are able to see themselves in the role of a scientist their interest and positivity towards STEM related topics will increase.

\subsubsection{Facilitate Positivity and Curiosity}

It is also important to make sure that girls have positive experiences when engaging in STEM related lessons. When positive feelings are associated with STEM, girls are more likely to find it pleasurable and continue to be engaged and interested. These positive experiences will improve students' STEM identity which Hughes et al. (2013) call "their ability to see themselves as the kind of people who could be legitimate participants in STEM through their interest, abilities, race and gender" (p.1).

Not only do girls need to have positive experiences, but girls also need to be given the freedom to explore, ask questions, be curious, and be creative. Many times in STEM related fields there are prescribed procedures (Banchi \& Bell, 2008). Instead, fuel students' curiosity through creative thinking and problem solving.

One research study focused on forming a program specifically aimed at creating positive environments for girls to interact with STEM ideas. Specifically, in this experiment, girls were asked to design, use communication technologies, and have structured interactions with information technology professionals to integrate STEM related concepts into a project. As part of the experiment, the girls in the study were interviewed before and after the implementation of working with the designated STEM concepts. It is important to note that in this experiment there was a control group. The results showed that the participants in the experimental group, the group that engaged in structured STEM interactions, had a more positive view compared to the control group. From this study, the researchers concluded that experiencing structured, engaging, and positive STEM concepts influenced and expanded girls' future career options to include STEM professions (Koch, Georges, Gorges, \& Fujii, 2010).

\subsubsection{Peer STEM Learning Environments}

Developing a classroom full of curious minds can also lead to a classroom of informal STEM learning environments, which is a great way to incorporate all of the above suggestions in a low pressure situation. Informal learning environments, such as STEM after school club or summer camps, take grades out of the equation and allows girls to explore STEM as an interest or hobby, rather than being linked to a grade or academics. Dasgupta and Stout (2014) suggest afterschool STEM camps as a research based strategy for increasing girls' exposure to STEM, which has the potential to open up opportunities to explore science and technology through hands-on activities such as coding clubs, robotics clubs, or science-art summer camps. One example is an after school STEM program for girls that reported in both program years studied, twice as many participants aspired to be engineers at the end of the program as at the beginning (Moustache,Nieves, Kekelis, and Lawner, 2013). Overall, creating positive and open environments for girls to explore STEM will increasingly assist in closing the prevailing gender gap.

\section{DISCUSSION}

There is a gender gap in STEM professions. Research suggests that it begins in childhood when children are socialized within families and with peers. The effects of this socialization are apparent in society by reporting how many females are in STEM professions, how many females enroll in STEM undergraduate programs, and how many adolescents engage in STEM focused content. It has been stated the most girls lose interest in STEM topics between the ages of nine to twelve (Goodwin, 2013). While movements and curricula are striving to combat this reality, the mentalities and embedded socialized constructs need to be questioned and changed. However, it is also important to remember that, while there is still a gender gap, girls have been entering the STEM field at an increasing rate over the last twenty years.

Researchers have studied the socialized stereotypes placed on girls and boys at a young age. They have focused on the idea of peer groups and how the developmental stage of adolescence could influence STEM choices. Researchers have also studied how the stereotypes of STEM professions might influence or discourage females from entering the STEM field. While each of these assumptions may influence the gender gap focused in STEM professions, it is also important to note what is and can be done to continually decrease the gender gap between males and females in STEM.

\section{CONCLUSION}

The overall goal and purpose of this study was investigate and summarize current scholarship focused on girls and STEM. While the 2010 President's Council of Advisor on Science and Technology indicated that there was a need to provide individuals with strong STEM backgrounds in order to be a competitive country internationally, it is important to concentrate on both genders while achieving that mission. While access to STEM content provides momentum to close the gender gap, many argue that addressing the underlying culture of socialization, peer pressure, and marginalization needs to also occur in society (Bianchini et al. 2000; Brotman and Moore 2008). As outlined in this article, the culture of marginalization will only be improved by providing continued STEM experiences, professional women role models, building positivity, and fostering curiosity about the potential of STEM applications and/or careers.

The strategies discussed in this article are important, such as creating positive and curious environments. However, it is also important to continue to educate boys in STEM fields. As professionals and researchers, it is important to remember that if the pendulum swings too much the other way, boys will be marginalized in STEM fields. Furthermore, it should be the goal of advocates and educators to close the gender gap and not create a gender gap in the opposite direction.

\section{REFERENCES}

Banchi, H., \& Bell, R. (2008). The many levels of inquiry. Science and Children. Retrieved from http://static.nsta.org/files/sc0810_26.pdf

Bianchini, J. A., Cavazos, L. M., \& Helms, J. V. (2000). From professional lives to inclusive practice: science teachers and scientist views of gender and ethnicity in science education. Journal of Research in Science Teaching, 37, 511-547. doi:10.1002/1098-2736(200008)37:6<511::AID-TEA2>3.0.CO;2-3

Brotman, J. S., \& Moore, F. M. (2008). Girls and science: a review of four themes in the science education literature. Journal of Research in Science Teaching, 45(9), 971-1002. doi:10.1002/tea.20241

Burton, M. D. (1986). Gender differences in professional socialization: A study of women and men in the computer science (Doctoral dissertation). Retrieved from http://repository.cmu.edu/cgi/viewcontent.cgi?article=1037\& context=hsshonors 
Cheryan, S., Master, A., \& Meltzoff, A. N. (2015). Cultural stereotypes as gatekeepers: Increasing girls' interest in computer science and engineering by diversifying stereotypes. Frontiers in Psychology, 6, 49. doi:10.3389/fpsyg.2015.00049

Crawford, M. (2012). Engineering still needs more women. American Society of Mechanical Engineers. Recuperado de http://www.asme.org/career-education/ articles/undergraduate-students/engineering-still-needs-more-women

Crosnoe, R., Riegle-Crumb, C., Frank, K., Field, S., \& Muller, C. (2008). Peer group contexts of girls' and boys' academic experience. Child Development, 79(1), 139-155. doi:10.1111/j.1467-8624.2007.01116.x

Dasgupta, N., \& Stout, J. G. (2014). Girls and women in science, technology, engineering, and mathematics: STEMing the tide and broadening participation in STEM careers. Policy Insights from the Behavioral and Brain Sciences, 1(1), 21-29. doi:10.1177/2372732214549471

Eccles, J. S. (2014). Gendered socialization of STEM interests in the family. 2nd Network Gender \& STEM Conference. Berlin, Germany. Retrieved from file://C:/Users/anreink/Downloads/419-2943-1-PB.pdf

Girls, Inc. (2016). Science, Math, and Relevant Technology. Retrieved from http:// www.girlsinc.org/resources/programs/girls-inc-operation-smart.html

Goldie Blox, Inc. (2017). Retrieved from https://www.goldieblox.com/pages/about

Gunderson, E. A., Ramirez, G., Levine, S. C., \& Beilock, S. L. (2011). The role of parents and teachers in the development of gender related math attitudes. Sex Roles, 66(3), 153-166.

Hayden, K., Ouyang, Y., Scinski, L., Olszewski, B., \& Bielefeldt, T. (2011). Increasing student interest and attitudes in STEM: Professional development and activities to engage and inspire learners. Contemporary Issues in Technology and Teacher Education, 11(1), 47-69.

Hill, C., Corbett, C., \& St. Rose, A. (2010). Why so few? Women in science, technology, engineering, and mathematics. AAUW. Retrieved from https://www. aauw.org/files/2013/02/Why-So-Few-Women-in-Science-Technology-Engineering-and-Mathematics.pdf

Hughes, R. M., Nzekwe, B., \& Molyneaux, K. J. (2013). The single sex debate for girls in science: A comparison between two informal science programs on middle school students' STEM identity formation. Research in Science Education, 43(5). doi:10.1007/s11165-012-9345-7

Kerpen, C. (2017). How a confidence mindset can help close the gender gap in STEM.Women@Forbes. Retrieved from https://www.forbes.com/sites/carriekerpen/2017/06/21/how-confidence-mindset-can-help-close-the-gender-gapin-stem/\#650222e66708

Koch, M., Georges, A., Gorges, T., Fujii, R., (2010). Engaging youth with STEM professionals in afterschool programs. Meridian: A Middle School Computer Technologies Journal, 13(1). Retrieved from https://www.ncsu.edu/meridian/ winter2010/koch $/ 07 . h t m$

Leaper, C. (2014). Parents' socialization of gender in children. Encyclopedia on Early Childhood Development. Retrieved from http://www.child-encyclopedia. com/gender-early-socialization/according-experts/parents-socialization-gender-children

Leaper, C., Farkas, T., \& Brown, C. S. (2011). Adolescent girls' experiences and gender-related beliefs in relation to their motivation in math/science and English. Journal of Youth and Adolescence, 41(3), 268-282. doi:10.1007/s10964011-9693-Z

Milgram, D. (2011). How to recruit women and girls to the science, technology, engineering, and math (STEM) classroom. Technology and Engineering Teacher, $71(3), 4-11$.

Mosatche, H. S., Matloff-Nieves, S., Kekelis, L., \& Lawner, E. K. (2013). Effective STEM programs for adolescent girls: Three approaches and many lessons learned. Afterschool Matters, 17, 17-25.

National Academy of Engineering. (2017). Retrieved from https://www.nae.edu/.

National Science Foundation. (2012). Report: Women, Minorities, and Persons with Disabilities. Science and Engineering. Retrieved from https://www.nsf.gov/statistics/2017/nsf17310/

Parke, P. (2014, October 27). Ask the experts: How do we get girls into STEM? CNN World. Retrieved from http://www.cnn.com/2014/10/27/world/europe/how-toget-girls/

Partridge, J., Brustad, R., Stellino, M. B. (2008). Social influence in sport. In T. S. Horn (Ed.), Advances in Sport Psychology (pp. 269-292). Champaign: Human Kinetics.

Shapiro, J. R., \& Williams, A. M. (2012). The role of stereotype threats in undermining girls' and women's performance and interest in STEM fields. Sex Roles, 66, 175-183. doi:10.1007/s11199-011-0051-0

SparkNotes Editors (2006). SparkNote on Socialization [Report]. Retrieved from http://www.sparknotes.com/sociology/socialization/

Steinke, J. (2017). Adolescent girls' STEM identity formation and media images of STEM professionals: Considering the influence of contextual cues. Frontiers in Psychology, 8, 716. doi:10.3389/fpsyg.2017.00716

Ulaby, N. (2013). Girls' Legos are a hit, but why do girls need special Legos? NPR: Weekend Edition Saturday. Retrieved from http://www.npr.org/sections/monkeysee/2013/06/28/196605763/girls-legos-are-a-hit-but-why-do-girls-need-special-legos van Hoorn, J., van Dijk, E., Meuwese, R., Rieffe, C., \& Crone, E. (2016). Peer influence on prosocial behavior in adolescence. Journal of Research on Adolescence, 26(1), 90-100. doi:10.1111/jora.12173

You, S. (2011). Peer influence and adolescents' school engagement. Procedia-Social and Behavioral Sciences, 29, 829-835. doi:10.1016/j.sbspro.2011.11.311

How to cite this article: Reinking, A., \& Martin, B. (2018). The Gender Gap in STEM Fields: Theories, Movements, and Ideas to Engage Girls in STEM. Journal of New Approaches in Educational Research, 7(2), 148-153. doi: $10.7821 /$ naer.2018.7.271 